vezes, sempre de acordo com as indicações do fabricante. Após a inserção de cada implante, a estabilidade primária foi medida três vezes com o método da análise de frequência de ressonância através do dispositivo Osstell ${ }^{\circledR}$ Mentor (Osstell, Gotemburgo, Suécia). Para comparar os resultados entre o grupo de controlo e os grupos teste foi utilizado o T-test e o teste de Mann-Whitney, sendo que para comparações entre os grupos teste foi usado o teste de Kruskal-Wallis, com um nível de significância de $5 \%$.

Resultados: Os resultados sugerem que existem diferenças estatisticamente significativas nos valores da estabilidade primária entre o grupo A e os grupos B, C e D $(p<0,05)$. Verifica-se que, em média, o grupo de $A$ apresenta valores de estabilidade primária significativamente superiores aos grupos B, C e D. Para além disso, observam-se diferenças estatisticamente significativas nos valores da estabilidade primária entre o grupo B e os grupos C e D ( $p<0,05)$, verificando-se que, em média, o grupo B apresenta valores significativamente superiores aos grupos C e D.

Conclusões: Dentro das limitações do presente estudo in vitro, os resultados sugerem que a estabilidade primária dos implantes curtos é menor que a dos implantes com comprimentos standard, em osso de baixa densidade.

http://doi.org/10.24873/j.rpemd.2018.11.430

\#115 Avaliação tridimensional dos resultados clínicos obtidos pela Técnica Tunelização ETC

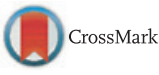

David Simões e Martins*, Luís Pereira Azevedo, Nuno Malta Santos, Tiago Miguel Marques, Célia Coutinho Alves, André Correia

ICS-Viseu UCP

Objetivos: Avaliar, de forma prospetiva, o recobrimento radicular e o aumento da espessura gengival, em RG unitárias, tratadas com a técnica de tunelização modificada por Zuhr em 2007.

Materiais e métodos: Estudo prospetivo de coorte preliminar, num período de 6 meses. Três tempos de avaliação: dia da cirurgia (T0), 3 meses (T1) e 6 meses depois da cirurgia (T2). Amostra: 2 pacientes, com 3 RG unitárias maxilares e mandibulares, classes I de Miller. Protocolo cirúrgico: adaptado de Zuhr em 2007. Técnica de tunelização microcirúrgica modificada associada a um enxerto de tecido conjuntivo: realizaram-se incisões sulculares. De seguida, elevou-se um túnel supraperiósteo com extensão para além da linha mucogengival, bem como um dente para mesial e outro para distal, do dente a ser tratado. Fez-se colheita de um enxerto gengival livre, do palato lateral, desepitelizado extra-oralmente, segundo Zucchelli descreve em 2013. Introduziu-se o ETC no túnel previamente preparado, tendo sido fixo com sutura de nylon 6-0, nas extremidades do túnel. Fez-se reposição do retalho, $2 \mathrm{~mm}$ coronal à linha amelocementária dos dentes incluídos, com suturas suspensas ancoradas, às faces vestibulares, e com a técnica 'double crossed suture', ancorada aos pontos de contacto. Variável principal analisada: espessura gengival obtida, na superfície radicular recoberta. Para esta análise tridimensional dos tecidos, efetuaram-se modelos de estudo em T0, T1 e T2. Estes foram digitalizados com um scanner intra-oral DentalWings ${ }^{\circledR}$, obtendo-se um ficheiro STL para cada situação. No programa informático Geomagic Control $\mathrm{X}^{\circledR}$, efetuou-se a comparação tridimensional das áreas intervencionadas. Variável secundária analisada: percentagem de recobrimento radicular (\% RR), através de medições nos modelos digitais, no programa informático Geomagic Control $\mathrm{X}^{\circledR}$.

Resultados: Valores médios: Ganho espessura gengival (T0-T1: 0,59 mm; T1-T2: 0,22 mm; T1-T2: 0,81 mm); RG T0=1,00 $\mathrm{mm}$; RG residual T2=0,36 mm; \%RR T2=66,58\%.

Conclusões: Dentro das limitações deste estudo - tamanho da amostra e tempo de seguimento pós-operatório - pode-se verificar que a técnica de cirurgia plástica periodontal utilizada permite obter um recobrimento radicular com sucesso e aumentar consideravelmente a espessura gengival em casos de RG unitárias, Classes I de Miller.

http://doi.org/10.24873/j.rpemd.2018.11.429

\#116 Avaliação estética dos resultados clínicos de duas técnicas de recobrimento radicular

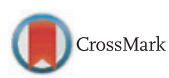

Luís Pereira Azevedo*, David Simões e Martins, Nuno Malta Santos, Tiago Miguel Marques, Célia Coutinho Alves, André Correia

ICS-Viseu UCP

Objetivos: Analisar e comparar, de forma retrospetiva, as avaliações estéticas dos Periodontologistas e dos Pacientes, sobre os resultados clínicos obtidos por duas técnicas de recobrimento radicular.

Materiais e métodos: Estudo retrospetivo de coorte preliminar, num período de 6 meses. Foram realizadas fotografias intraorais, a cada paciente, em dois tempos de avaliação: dia da cirurgia (T0) e 6 meses depois da cirurgia (T1). As mesmas foram apresentadas a dois Periodontologistas e aos Pacientes, para posterior classificação estética. Amostra: 5 pacientes, com 6 RG unitárias maxilares e mandibulares, classes I e III de Miller, tratadas respetivamente com um enxerto de tecido conjuntivo associado às técnicas Tunelização modificada e VISTA. Variáveis principais analisadas: Avaliação estética dos resultados clínicos obtidos, em T1; Periodontologistas: segundo o 'Root Coverage Aesthetic Score' (RES), proposto por Cairo em2009; Pacientes: segundo uma escala analógica visual (0-10). Variáveis secundárias analisadas: Classificação das recessões gengivais (RGs), segundo Miller, em T0; Profundidade das RGs, em T0, e das RGs residuais, em T1, pela medição nos modelos digitais, no programa informático Geomagic Control $\mathrm{X}^{\circledR}$; Percentagem média de recobrimento radicular $(\%$ média RR), em T1.

Resultados:.RG Classes I de Miller, com profundidade média de 1,00 mm, tratadas com a técnica Tunelização modificada ETC, apresentavam uma profundidade média residual de 0,36 mm (\% média RR = 66,58\%), em T1. Avaliações estéticas segundo Pacientes e Periodontologistas: 9,33 e 8,50, respetivamente. RG Classes III de Miller, com profundidade média de 3,27 mm, tratadas com a técnica VISTA ETC, apresentavam uma profundidade média residual de $0,78 \mathrm{~mm}$ (\% média $\mathrm{RR}=$ 
80,73\%), em T1. Avaliações estéticas segundo Pacientes e Periodontologistas: 9,33 e 6,17, respetivamente.

Conclusões: Dentro das limitações deste estudo - tamanho da amostra e tempo de seguimento pós-operatório - pode-se verificar que: Há discrepâncias entre as avaliações estéticas realizadas pelos Periodontologistas e pelos Pacientes. A perceção estética do paciente parece ser mais influenciada pela integração dos tecidos moles com os tecidos adjacentes e a perceção estética dos Periodontologistas parece ser mais influenciada pela quantidade de recobrimento radicular; As duas técnicas de cirurgia plástica periodontal permitem obter um recobrimento radicular com sucesso, em casos de RG unitárias, Classes I e III de Miller.

http://doi.org/10.24873/j.rpemd.2018.11.428

\section{\#117 Avaliação in vitro de cadeias elásticas quando expostas a soluções de clorexidina}

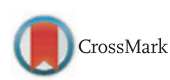

Rita Passos Gancho, Pedro Mariano Pereira*, Madalena Salema Oom, Luís Proença

Instituto Universitário Egas Moniz

Objetivos: As cadeias elásticas ortodônticas são dispositivos utilizados em ortodontia como fontes de transmissão de força aos dentes. Contudo a força das cadeias decresce ao longo do tempo, condicionando o movimento dentário. Os pacientes ortodônticos apresentam maior suscetibilidade à doença periodontal, pois a higiene oral está dificultada, exigindo um controlo mecânico e químico rigoroso. A clorexidina é um dos agentes antibacterianos mais utilizados e eficaz no controlo químico do biofilme. Existe pouca informação sobre o efeito do digluconato de clorexidina nestes materiais justificando-se a realização deste estudo. Assim, pretende-se avaliar a influência de soluções de digluconato de clorexidina, em concentrações idênticas às encontradas nos colutórios orais, na degradação das cadeias elásticas ortodônticas.

Materiais e métodos: Foram testadas cadeias elásticas de três marcas diferentes: $3 \mathrm{M}$ Unitek ${ }^{\circledR}$, Ormco ${ }^{\circledR}$, e TP Orthodonti$\mathrm{Cs}^{\circledR}$, as quais sofreram um estiramento de $50 \%$ do seu comprimento inicial, e mantidas em saliva artificial a $37^{\circ} \mathrm{C}$ simulando as condições da cavidade oral. Foram criados três grupos, o grupo controle que foi mantido durante todo o período experimental em saliva artificial e dois grupos de estudo em que as cadeias foram submersas diariamente durante 60 segundos, em duas soluções de digluconato de clorexidina (a $0.12 \%$ ou a 0.2\%). Após 0, 7, 14 e 28 dias foi avaliada a força, usando um dinamómetro, e a resistência à tração, através da máquina de testes universais.

Resultados: A submersão diária em digluconato de clorexidina a $0.12 \%$ e $0.2 \%$ afetou a força das cadeias, existindo uma deterioração superior à sofrida pelo grupo controlo $(p=0.003$ e $\mathrm{p}<0.001$ respetivamente). Verificou-se ainda, que as cadeias submersas na solução a $0.2 \%$ sofreram uma perda de força superior quando comparadas com as submersas na solução a $0.12 \%(p=0.023)$. Não se verificaram diferenças significativas na resistência à rutura das cadeias expostas à solução de $0.12 \%$ $(\mathrm{p}=0.233)$, contrariamente ao que se verificou com as cadeias submersas na solução a $0.2 \%(p=0.027)$. Verificou-se ainda diferenças significativas $(p<0.001)$ entre marcas, quer para a força quer para a resistência à rutura.

Conclusões: O uso diário de soluções de digluconato de clorexidina a $0.12 \%$ e a $0.2 \%$ parecem interferir na força das cadeias elásticas ao longo do tempo, contudo apenas a solução a $0.2 \%$ parece afetar a resistência à rutura.

http://doi.org/10.24873/j.rpemd.2018.11.427

\#118 Avaliação in vitro de cadeias elásticas quando expostas a soluções de flúor

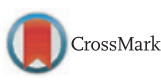

Rita Passos Gancho*, Pedro Mariano Pereira, Madalena Salema Oom, Luís Proença

Instituto Universitário Egas Moniz

Objetivos: As cadeias elásticas ortodônticas são dispositivos utilizados em ortodontia como fontes de transmissão de força aos dentes. Contudo a força das cadeias decresce ao longo do tempo, condicionando o movimento dentário. Os pacientes ortodônticos apresentam maior suscetibilidade à desmineralização dentária, pois a higiene oral está dificultada, exigindo um controlo mecânico e químico rigoroso. A prescrição de flúor, através de colutórios orais, tem vindo a disseminar-se na Medicina Dentária, devido ao seu papel preventivo nessa desmineralização dentária. Existe pouca informação sobre o efeito do flúor nestes materiais justificando-se a realização deste estudo. Assim, pretende-se avaliar a influência de soluções de fluoreto de sódio, em concentrações idênticas às encontradas nos colutórios orais, na degradação das cadeias elásticas ortodônticas.

Materiais e métodos: Foram testadas cadeias elásticas de três marcas diferentes: $3 \mathrm{M}$ Unitek ${ }^{\circledR}$, Ormco ${ }^{\circledR}$ e TP Orthodonti$\mathrm{Cs}^{\circledR}$, as quais sofreram um estiramento de $50 \%$ do seu comprimento inicial, e mantidas em saliva artificial a $37^{\circ} \mathrm{C}$ simulando as condições da cavidade oral. Foram criados três grupos, o grupo controle que foi mantido durante todo o período experimental em saliva artificial e dois grupos de estudo em que as cadeias foram submersas diariamente durante 60 segundos, em soluções de fluoreto de sódio a 248 ppm ou a 500 ppm de flúor. Após 0, 7, 14 e 28 dias foi avaliada a força, usando um dinamómetro, e a resistência à tração, através da máquina de testes universais.

Resultados: A submersão diária em fluoreto de sódio a 248 e a 500 ppm de flúor afetou a força das cadeias elásticas $(p<0.001)$, existindo uma deterioração superior à sofrida pelo grupo controlo nas cadeias expostas à solução contendo 500 ppm de flúor ( $\mathrm{p}=0.001)$. O ponto de rutura não foi afetado significativamente em ambas as soluções a 500 ppm e 248 ppm de flúor ( $p=0.134$ e $p=0.114$ respetivamente). Verificou-se ainda diferenças significativas $(p<0.001)$ entre marcas, quer para a força quer para a resistência à rutura.

Conclusões: O uso diário das soluções de higiene oral de fluoreto de sódio parece interferir na degradação das cadeias elásticas, afetando a sua força ao longo do tempo, mas não parecem interferir com a resistência à tração.

http://doi.org/10.24873/j.rpemd.2018.11.426 